\title{
On Monetary Policy and Stock Price Relationship: Long and Short-run Dynamics
}

\author{
Sakshi Saini and Sanjay Sehgal ${ }^{* *}$
}

\begin{abstract}
In this paper, we investigate the relationship between monetary policy and stock prices across advanced and emerging economies from January 1999 to December 2017. We also examine the impact of global monetary policy on the sample stock markets. Using the Structural Cointegrated Vector-Autoregressive model, we explore long-run equilibrium relationship and short-run dynamics of monetary policy and stock markets before and after the global financial crisis. Our results demonstrate that domestic policy rate and stock prices are often not tied together in long-term equilibrium relationships for a majority of the economies. Cross-sectional heterogeneity is observed as the relationship differs in terms of sign, magnitude and adjustment dynamics. Further, US monetary conditions are found to play an important role in influencing global output or liquidity conditions. Short-run dynamics reveal a positive impact of expansionary monetary policy shock on equity prices in those economies where transmission mechanism of monetary policy is weak. Further, we find limited response of central banks to domestic equity price shocks. The influence of US monetary policy shocks in driving equity prices is also found to be insignificant for a majority of the economies.
\end{abstract}

Keywords: Monetary policy, Stock price, Structural Cointegrated VAR, Impulse responses

\section{INTRODUCTION}

The monetary authorities of major advanced economies (like Federal Reserve, European Central Bank, Bank of England, Bank of Japan) started pursuing expansionary monetary policy after the global financial crisis of 2008 to boost their economies. However, the interest rates soon reached low levels after which further rate cuts were not possible. Consequently, central banks started targeting long-term interest rates by adopting unconventional monetary policy tools in the form of large scale asset purchases. Interest rates remained low for a protracted period of time leading to excessive liquidity and huge fluctuations in the asset prices. This triggered financial instability and sparked the debate on whether monetary policy should counteract excessive fluctuations in asset prices to ensure financial stability. The crisis, thus, has prompted the policymakers and academicians to examine the dynamic relationship of monetary policy and stock prices.

\footnotetext{
Research Scholar, Department of Financial Studies, University of Delhi, Delhi, India E-mail: s.sakshi1408@gmail.com (Corresponding Author)

** Professor, Department of Financial Studies, University of Delhi, Delhi, India
} 
The monetary policy aims to ensure price and output stability in an economy. However, in the aftermath of the crisis, the need to ensure financial stability through monetary policy is well recognized by both policymakers as well as the academic community. Dividend Discount model provides an explanation for the possible impact of monetary policy on stock prices. Expansive monetary policy induces stock price rise by reducing the rate at which cash flows are discounted, thereby increasing future expected cash flows.

A large body of empirical literature has focused its attention on determining the linkages of monetary policy and stock prices. Rigobon and Sack (2004) examine the impact of the Federal Reserve's monetary policy on stock price changes and find a negative impact of interest rates on stock prices. Bernanke and Kuttner (2005) also report that expansionary monetary policy leads to stock price rise in the US and further documents that the response of stock price to monetary policy is predominantly explained by expected excess returns. Basistha and Kurov (2008) document a strong impact of unexpected monetary policy changes on stock return during recessionary times. Bjornland and Leitemo (2009) use Structural VAR (SVAR) model and find strong linkages between monetary policy and real stock prices. They report that stock prices fall due to contractionary monetary policy shock, on the other hand, interest rates rise as a result of positive stock price shock. Li et al. (2010) also examine the impact of monetary policy shocks on stock prices in Canada and the US by employing the SVAR model and find that the magnitude and duration of the impact of monetary policy on stock price are high in the US as compared to Canada. Laopodis (2013) investigates the linkages of monetary policy and stock prices during the monetary regime of Burns, Volcker and Greenspan since the 1970s and report different nature of dynamics in each of the three monetary regimes. More recently, Eksi and Tas (2017) investigate the effect of the US monetary policy on stock returns after the global financial crisis of 2008 when Federal Reserve started to use unconventional policy tools and find that the impact of monetary policy on stock returns increased in the magnitude after the interest rates reached zero lower bound. Fausch and Sigonius (2018) also investigate the effect of conventional and unconventional monetary policy of the European Central Bank on German stock returns. They report that monetary policy tightening engenders fall in excess stock returns during periods of negative real interest rates. Latha et al. (2017) examine the impact of interest rates volatility on the portfolio of stock returns and document that if interest rate becomes more volatile it would also increase the volatility of conditional stock returns. The majority of the research focuses on the US or European stock markets, while crosscountry studies are relatively scarce. Ioannidis and Kontonikas (2008) report a considerable stock return response to the monetary policy shock in 13 OECD countries. Suhaibu et al. (2017) find a contemporaneous relationship of monetary policy and stock prices in 12 African economies. Abouwafia and Chambers (2015) study the interdependence between monetary policy and stock prices in 5 economies of the Middle East and report heterogeneity in their interaction.

Belke and Beckmann (2015) use the Cointegrated VAR model to study the long-run relationships and short-run dynamics of monetary policy and equity market interaction in 5 advanced and 3 emerging economies and find different patterns and causalities for these economies. They find a direct relationship of monetary policy on stock prices in the long run for 3 out of 8 economies including the US, Thailand and Brazil, while significant short-run dynamics are hardly identified. Apart from Belke and Beckmann (2015), no other study has analyzed long-run equilibrium relationships and short-run dynamics of monetary policy and stock price.

Stock markets being highly sensitive to monetary policy actions, it is worthwhile to study the relationship between monetary policy and stock prices as it can help in understanding monetary policy transmission mechanism and formulating effective policy decisions. To the best of our knowledge, there is a lack of comprehensive evidence in the literature on long-run relationships and short-run dynamics of monetary policy and stock market interaction, except the study by Belke and Beckmann (2015) which focuses on 5 advanced and 3 emerging economies. Further, most of the previous studies have not analyzed the relationship between monetary policy and stock prices 
period before and after the crisis as the dynamics may differ across the two sample periods because of the use of unconventional policy tools by the central banks of advanced economies after the crisis. The paper is an attempt to fill this void in the empirical literature.

In this light, this paper aims to study the relationship between monetary policy and stock prices from January 1999 to December 2017 by exploring their long-run equilibrium relationships and short-run dynamics by employing Structural Cointegrated Vector-Autoregressive (VAR) model. We consider a wider selection of economies as compared to Belke and Beckmann (2015) as our analysis is based on a total of 15 economies, out of which 7 are advanced and 8 are emerging economies. We contribute to the literature by undertaking a systematic analysis of their relationship in both short and long term for a larger set of major developed and developing economies. We further assess the impact of US monetary policy on domestic equity markets. Hence, our study is based on two strands of the literature as we focus not only on the domestic monetary policy but also on the global monetary policy in influencing the stock prices of the sample economies. Further, we undertake our analysis in two subperiods - before and after the global financial crisis to make a comparative assessment of whether the relationship of monetary policy and equity prices altered in the aftermath of the crisis.

The study will be relevant for monetary authorities and policymakers in envisaging the monetary policy transmission to equity prices and thus, will help them in formulating effective policies. It will also be crucial for market participants in making investment decisions. Further, it will contribute to the literature on the relationship of monetary policy and stock prices for major advanced and emerging economies before and after the crisis.

The paper is organized as follows. Section 2 describes the methodological framework. Section 3 presents the data. Section 4 discusses the empirical results and their implications. The final section presents the conclusion.

\section{METHODOLOGY}

VAR models are probably the most widely used model to examine relationships among a set of macroeconomic variables. A standard VAR model is usually modelled with stationary variables achieved through first differencing. However, this may lead to loss of information concerning long-term relationships and misspecification of the model if variables are found to be cointegrated (Hafer and Jansen, 1991). A Cointegrated VAR model allows a possible relationship to exist between the variables in the long-run by exploiting the nonstationary properties of the data. Macroeconomic time series are usually found to be $I(1)$, hence models should be estimated in differences, allowing for cointegration (Giese and Tuxen, 2007).

\section{Cointegration Analysis}

Considering a $p$-dimensional VAR $(k)$ model,

$X_{t}=\Pi_{1} X_{t-1}+\ldots+\Pi_{k} X_{t-k}+\Phi D_{t}+v_{t}$

where $X_{t} \sim I(1)$ is a vector of $p$ variables in period $t, t=1, \ldots, T . v_{t}$ is a vector of error terms that are independently and identically distributed with Gaussian distribution, $v_{t} \sim N_{p}(0, \Omega)$, where $\Omega$ is the variance-covariance $p$ xp matrix of the errors. $D_{t}$ is ${ }^{p} \bar{a}$ a vector of deterministic terms including intercept and trend term and $\Phi$ is a vector of unrestricted parameters. 
The reduced form vector error correction model which combines differences and levels of the process, obtained from reparametrization of(1), can be expressed in the following form:

$\Delta X_{t}=\Pi X_{t-1}+\Sigma \quad \Gamma_{i} \Delta X_{t-i}+\Phi D_{t}+v_{t}$

where, $\Pi=\sum_{i=1}^{k} \Pi_{i}-I_{p}$ and $\Gamma_{i}=\sum_{j=i+1}^{k} \Pi_{j}$.

$\Pi$ is a long-run $p \times p$ matrix that contains the long-run information of the data. It has a reduced $\operatorname{rank} r<p$ and can be written as: $\Pi=\alpha \beta$, , $\propto$ and $\beta$ are $p \times r$ matrices with $0 \leq r \leq p$. The factorization yields $r$ stationary cointegrating relations and $p-r$ common stochastic trends of the system. $\beta$ constitutes $r$ cointegration vectors such that $\beta^{\prime} X_{t}$ are the cointegrated relationships or the long-run equilibrium relationships that are stationary. Parameters in $\propto$ are the adjustment coefficients representing the speed of adjustment towards equilibrium for each variable. $\Gamma_{i}=\left(\Gamma_{1}, \ldots, \Gamma_{k}\right)$ are $p \times p$ short-run coefficient matrices and thus govern the short-run dynamics of the variables.

Substituting $\Pi=\alpha \beta$ ' in (2), we get an expression of the Cointegrated VAR model.

$\Delta x_{t}=\alpha \beta^{\prime} X_{t-1}+\sum_{i=1}^{p} \Gamma_{i} \Delta X_{t-i}+\Phi D_{t}+v_{t}$

The first step in estimating the Cointegrated VAR model is the determination of the cointegration rank. The existence of the long-run cointegrating relationships is determined by Johansen (1996) trace test for cointegration $\left(\gamma_{\text {trace }}\right)$. The cointegration rank divides the data into $r$ relations towards which the process is adjusting and $p-r$ relations which are pushing the system (Juselius, 2006). The cointegrating relations $(r)$ are interpreted as deviations from the steady-state equilibrium or the equilibrium errors, while $p-r$ relations that are pushing the system are regarded as the common driving trends. The next step is to identify the long-run structure by imposing restrictions on each of the unrestricted cointegrating vectors. The identification scheme involves applying restrictions to ensure generic identification, empirical identification and economic identification pertaining to overall identification of the statistical model, the significance of the estimated parameter values and economic interpretability of the estimated coefficients, respectively. The parameter estimates are obtained through full information maximum likelihood method subject to over-identifying restrictions on the long-run coefficients. Identification of $r$ long-run cointegrating relations requires at least $r-1$ restrictions on each relation.

\section{Short-run Structure}

Once the long-run structure has been identified, we turn to examine the short-run structure. A short run structure with $p$ equations constitutes $p$ current variables $\left(\Delta X_{t}\right), p(k-1)$ lagged variables $\left(\Delta X_{t-i}, i=1, \ldots, k-1\right)$ and $r$ lagged equilibrium errors $\left(\beta^{\prime} X_{t-1}\right)$. To examine the effects of fundamental shocks $\varepsilon_{t}$ on $X_{t}$, we express the shocks in terms of structural form VECM. The structural representation of (2) takes the following form:

$B \Delta X_{t}=\Psi X_{t-l}+\sum_{i=1}^{p} \Lambda_{i} \Delta X_{t-i}+\Phi D_{t}+\varepsilon_{t}$

where, $\varepsilon_{t}$ is a vector of orthogonal structural disturbances having covariance matrix $\Sigma_{\varepsilon}$.

Pre-multiplying (4) by $B^{-1}$ gives us reduced form (2) with $\Gamma_{i}=\left(B^{-1} \Lambda_{1}, \ldots, B^{-1} \Lambda_{p-1}\right)$ and $v_{t}=B^{-1} \varepsilon_{t}=\mathrm{A}_{0} \varepsilon_{t}$. We need to impose identifying restrictions on the residual covariance matrix based on economic theory to analyse the effects 
of underlying structural shocks. Hence, we write structural shocks as: $\varepsilon_{t}=\mathrm{E}\left[\mathrm{v}_{\mathrm{t}} \mathrm{v}_{\mathrm{t}}^{-1}\right]=\mathrm{A}_{0} \mathrm{E}\left[\varepsilon_{\mathrm{t}} \varepsilon_{\mathrm{t}}^{-1}\right] \mathrm{A}_{0}^{\prime}=\mathrm{A}_{0} \Sigma_{\varepsilon} \mathrm{A}_{0}^{\prime}$

We assume that structural shocks are uncorrelated and have unit variances, $\Sigma_{\varepsilon}=I_{B}$, such that $\varepsilon_{v}=\mathrm{A}_{0} \mathrm{~A}_{0}{ }_{0}$. It is worth noting that the identification of the contemporaneous coefficients $A_{0}$ and long-run coefficients $\beta$ are essentially two separate issues and restriction on $\beta$ have no mathematical implication for restrictions on $\mathrm{A}_{0}($ Cologni and Manera, 2008).

\section{DATA DESCRIPTION}

We undertake our analysis on 7 advanced countries - Canada (CAD), France (FR), Germany (GER), Italy (ITL), Japan (JPN), the United Kingdom (UK) and the United States (US), and 8 emerging economies including Brazil (BR), China (CHI), India (IND), Indonesia (IDN), Mexico (MEX), Russia (RUS), South Africa (SAF) and South Korea (SKOR). The policy rate set by the central banks is used as a proxy for monetary policy while the benchmark stock market index is used as a measure of equity prices in the sample economies. The policy rate and equity index considered for analysis for each of the sample countries is illustrated in Figure 1. We also consider macroeconomic variables as additional variables in our Cointegrated VAR model for each country: industrial production index, consumer price index (CPI), equity price index deflated by CPI, policy rate, 10-year government bond yield ${ }^{1}$, broad monetary aggregate M2 deflated by CPI to proxy for real output $\left(\mathrm{y}_{\mathrm{t}}\right)$, price index $\left(p_{t}\right)$, real equity prices $\left(s_{t}\right)$, monetary policy rate $\left(r_{t}\right)$, long-term interest rate $\left(l_{t}\right)$ and real monetary aggregate $\left(m_{t}\right)$, respectively. Monthly data for all the variables of each country from January 1999 to December 2017 has been retrieved from Bloomberg. The industrial production index and consumer price index of the sample countries are adjusted for seasonality using the X12-ARIMA procedure. Furthermore, all variables are expressed in natural logarithm except policy rate and long-term interest rate.

10-year government bond yield is not available for Brazil, China, Indonesia, Mexico and Russia over the sample period which ranges from January 1999 to December 2017; hence it is not included in the CVAR model for these countries. 


\section{Figure 1: Policy Rate and Benchmark Equity Index}

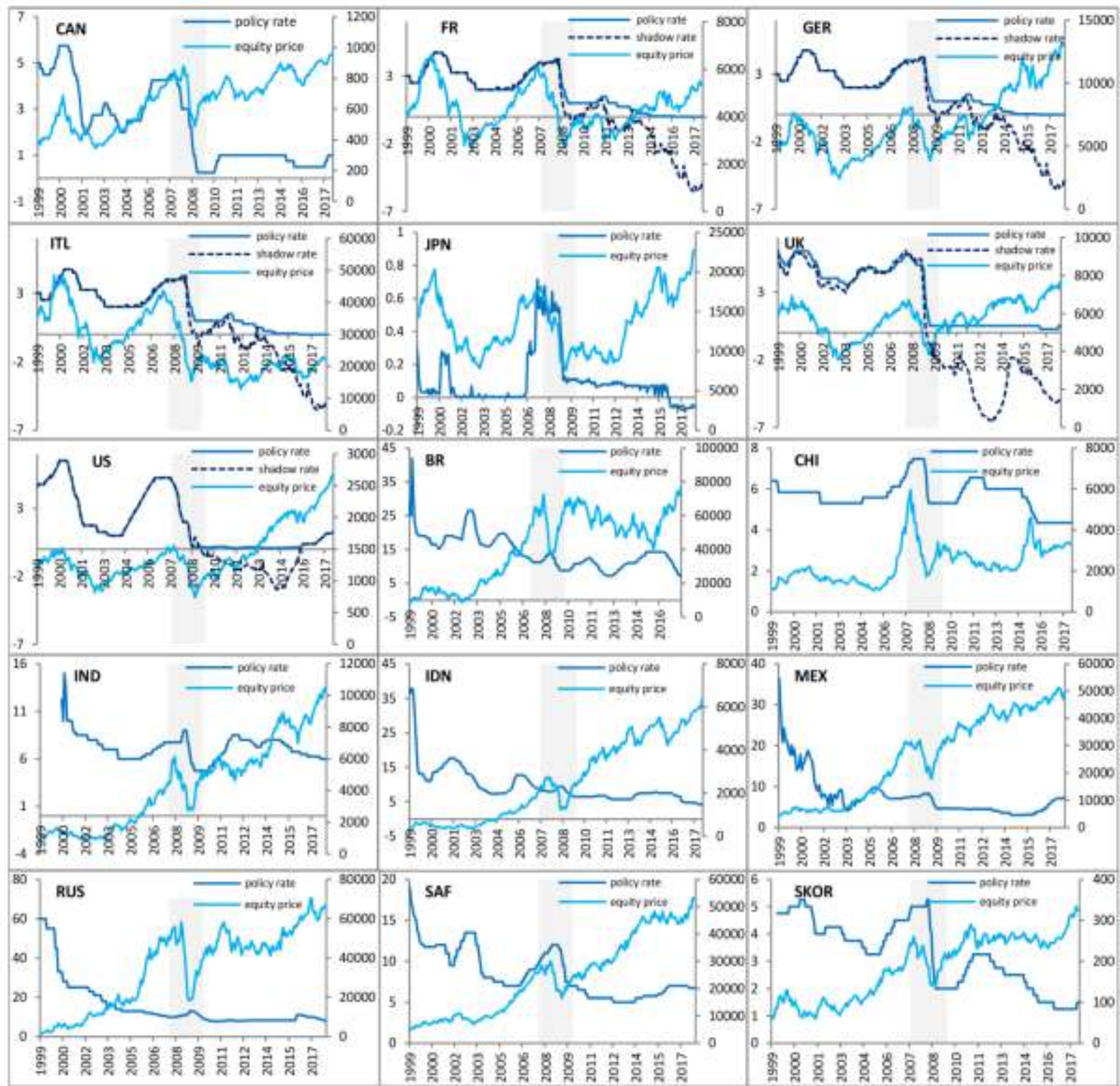

Notes: The figure displays policy rate and benchmark equity index of the sample advanced and emerging countries. CAN, FR, GER, ITL, JPN, UK and US denote Canada, France, Germany, Italy, Japan, the United Kingdom and the United States, respectively which are the sample advanced economies. BR, CHI, IND, IDN, MEX, RUS, SAF and SKOR denote Brazil, China, India, Indonesia, Mexico, Russia, South Africa and South Korea, respectively which are the sample emerging economies. Policy rate is plotted on the primary axis and benchmark equity price index is plotted on the secondary axis. Horizontal axis displays time (in years). The highlighted (in grey) portion indicates the crisis period ranging from August 2007 to October 2009. For description of the policy rate and benchmark equity index of the sample countries, see Appendix A1.

Source: Bloomberg

To account for the impact of US monetary policy on the domestic stock markets, we include the US monetary policy rate as an exogenous factor in the model for the rest of the sample economies. Since the US Federal Reserve used unconventional monetary policy strategies to revive the economy after the global financial crisis of 2008, we use shadow federal funds rate proposed by Wu and Xia (2016) to proxy the US monetary policy stance. We also 
use the shadow rate of UK and European Central Bank $(\mathrm{ECB})^{2}$ to capture their unconventional monetary policy strategies $^{3}$ during the zero lower bound environment provided by Wu and Xia (2016). We divide our sample period into the pre-crisis and post-crisis period and exclude the crisis period from the analysis that ranges from August 2007 to October 2009 (see Trichet, 2009; Angelini et al., 2011; Sehgal et al., 2016). Dividing the sample period into two sub-samples permits us to get rid of any statistical disturbance caused by the global financial crisis.

\section{RESULTS}

\section{Rank Determination and Diagnostics}

We employ the Structural Cointegrated VAR model to investigate monetary policy and stock market interaction in the long and short run in the sample countries for the pre-crisis and post-crisis period. First, we examine the stationarity of the variables using the Augmented Dickey-Fuller test and find the majority of the variables to be non-stationary in levels ${ }^{4}$. We now proceed to assess the optimal lag length of the model by employing HannanQuinn (H-Q) and Schwartz (SC) criterion ${ }^{5}$, which are the two well-known information criteria for optimal lag length selection. Additionally, we check residual autocorrelation in the model using Lagrange Multiplier (LM) test for autocorrelation and include more lags, if needed, to remove left-over residual autocorrelation. Hence, the final choice of the lag length of the model is guided by H-Q and SC criterion along with the LM test. To check the further model specification and ensure valid statistical inference, we conduct multivariate misspecification tests including normality test and Autoregressive Conditional Heteroskedasticity (ARCH) test for each country model. The model is found to be well-specified for both the sub-sample periods (pre and post-crisis) of all countries ${ }^{6}$. Misspecification tests were not satisfied for the full sample model, which validates the breaking of sample periods into two sub-periods because of the presence of structural beak due to the global financial crisis.

The first step is to determine the number of stationary cointegrating relations or the cointegration rank which divides the data into $r$ relations towards which the process is adjusting and $p-r$ relations which are pushing the system. The choice of cointegration rank is pivotal as it governs further analysis (Juselius, 2006). We investigate the existence of the number of cointegrating relationships using Johansen (1996) trace test for cointegration $\left(\gamma_{\text {trace }}\right)$. Given the relatively small number of observations as our sample period is divided into two sub-samples, we use small-sample Bartlett corrected trace test statistics to determine the number of steady-state cointegrating relationships. Linear trend term is included in most of the cointegrating relationships as the majority of the series exhibit trending behaviour. Table 1 displays the cointegration test results obtained by applying the Cointegrated VAR model for each sample country over the two sub-periods. As can be seen from the table, all countries exhibit at least one reduced rank based on trace test for both pre and post-crisis periods. However, the Likelihood Ratio (LR) trace test is not the sole information criterion for determining the appropriate rank. We also take into account the modulus of the roots of the companion matrix and the significance of the $\propto$ coefficients to ensure the appropriate selection of the number of cointegrating relations.

2 European Central Bank (ECB) conducts the monetary policy operations for Eurozone countries including France, Germany and Italy that are the sample economies for this study.

3 Shadow rate of Wu and Xia (2016) for the US, UK and ECB are retrieved from https://sites.google.com/view/jingcynthiawu/shadowrates (accessed on May 11, 2018).

4 Results of Augmented Dickey-Fuller test are not presented due to brevity of space but are available on request.

Results of H-Q and SC criterion are not presented due to brevity of space but are available on request.

${ }^{6}$ Results of misspecification tests i.e. LM test for autocorrelation, normality test and ARCH test are not presented due to brevity of space but are available on request. 
Table 1: Trace Test Results

\begin{tabular}{|c|c|c|}
\hline & Pre-crisis & Post-crisis \\
\hline Advanced Economies & $\begin{array}{l}\text { Trace Test Statistic } \\
\mathrm{r}=0: 132.774[0.039] \\
\mathrm{r}=1: 85.977 \quad[0.306]\end{array}$ & $\begin{array}{l}\text { Trace Test Statistic } \\
\mathrm{r}=0: 132.245[0.043] \\
\mathrm{r}=1: 85.988\end{array}$ \\
\hline FR & $\begin{array}{l}r=0: 198.528[0.000] \\
r=1: 128.167[0.000] \\
r=2: 78.878[0.016] \\
r=3: 42.243[0.219]\end{array}$ & $\begin{array}{l}\mathrm{r}=0: 205.235[0.000] \\
\mathrm{r}=1: 113.473[0.004] \\
\mathrm{r}=2: 70.662[0.077]\end{array}$ \\
\hline GER & $\begin{array}{l}r=0: 276.997[0.000] \\
r=1: 137.353[0.000] \\
r=2: 87.160[0.004] \\
r=3: 49.362[0.067]\end{array}$ & $\begin{array}{l}\mathrm{r}=0: 162.282[0.000] \\
\mathrm{r}=1: 84.750[0.344]\end{array}$ \\
\hline ITL & $\begin{array}{l}\mathrm{r}=0: 292.402[0.000] \\
\mathrm{r}=1: 164.963[0.000] \\
\mathrm{r}=2: 105.588[0.000] \\
\mathrm{r}=3: 57.695[0.001] \\
\mathrm{r}=4: 34.091[0.022] \\
\mathrm{r}=5: 15.054[0.056]\end{array}$ & $\begin{array}{l}\mathrm{r}=0: 174.154[0.000] \\
\mathrm{r}=1: 99.471 \quad[0.055] \\
\mathrm{r}=2: 63.569[0.244]\end{array}$ \\
\hline JPN & $\begin{array}{l}r=0: 143.40[0.007] \\
r=1: 88.186[0.245]\end{array}$ & $\begin{array}{l}\mathrm{r}=0: 169.705[0.000] \\
\mathrm{r}=1: 103.905[0.027] \\
\mathrm{r}=2: 67.049[0.138]\end{array}$ \\
\hline UK & $\begin{array}{l}r=0: 196.346[0.000] \\
r=1: 123.619[0.000] \\
r=2: 63.116[0.237]\end{array}$ & $\begin{array}{l}\mathrm{r}=0: 174.061[0.000] \\
\mathrm{r}=1: 115.302[0.003] \\
\mathrm{r}=2: 71.766[0.064]\end{array}$ \\
\hline US & $\begin{array}{l}\mathrm{r}=0: 120.932[0.029] \\
\mathrm{r}=1: 82.977[0.121]\end{array}$ & $\begin{array}{l}\mathrm{r}=0: 125.992[0.012] \\
\mathrm{r}=1: 84.370[0.098]\end{array}$ \\
\hline \multicolumn{3}{|l|}{ Emerging Economies } \\
\hline BR & $\begin{array}{l}r=0: 109.504[0.010] \\
r=1: 66.009[0.160]\end{array}$ & $\begin{array}{l}r=0: 124.563[0.000] \\
r=1: 58.372[0.405]\end{array}$ \\
\hline $\mathrm{CHI}$ & $\begin{array}{l}\mathrm{r}=0: 174.240[0.000] \\
\mathrm{r}=1: 77.148[0.023] \\
\mathrm{r}=2: 41.351 \quad[0.252]\end{array}$ & 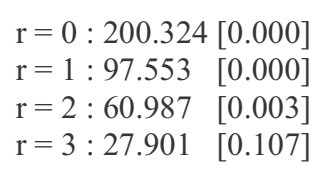 \\
\hline IND & $\begin{array}{l}r=0: 150.527[0.002] \\
r=1: 96.502[0.086]\end{array}$ & $\begin{array}{l}r=0: 191.474[0.000] \\
r=1: 122.705[0.001] \\
r=2: 73.632[0.046] \\
r=3: 36.065[0.496]\end{array}$ \\
\hline IDN & $\begin{array}{l}\mathrm{r}=0: 139.556[0.000] \\
\mathrm{r}=1: 69.138[0.099]\end{array}$ & $\begin{array}{l}\mathrm{r}=0: 102.248[0.035] \\
\mathrm{r}=1: 61.501 \quad[0.289]\end{array}$ \\
\hline MEX & $\begin{array}{l}r=0: 245.661[0.000] \\
r=1: 110.755[0.000] \\
r=2: 51.006[0.041] \\
r=3: 26.495[0.149]\end{array}$ & $\begin{array}{l}r=0: 173.959[0.000] \\
r=1: 113.160[0.000] \\
r=2: 60.670[0.004] \\
r=3: 30.075[0.062]\end{array}$ \\
\hline
\end{tabular}




$\begin{array}{lll} & \mathrm{r}=0: 166.887[0.000] & \mathrm{r}=0: 94.158[0.017] \\ \text { RUS } & \mathrm{r}=1: 98.419[0.000] & \mathrm{r}=1: 60.914[0.101] \\ & \mathrm{r}=2: 44.049[0.162] & \\ & \mathrm{r}=0: 147.752[0.003] & \mathrm{r}=0: 186.986[0.000] \\ \text { SAF } & \mathrm{r}=1: 93.280[0.134] & \mathrm{r}=1: 114.573[0.003] \\ & & \mathrm{r}=2: 71.734[0.064] \\ & & \\ \text { SKOR } & \mathrm{r}=0: 176.465[0.000] & \mathrm{r}=0: 152.742[0.001] \\ & \mathrm{r}=1: 115.180[0.003] & \mathrm{r}=1: 98.420[0.065]\end{array}$

Notes: Figure in parenthesis [ ] includes p-value. CAN, FR, GER, ITL, JPN, UK, US, BR, CHI, IND, IDN, MEX, RUS, SAF and SKOR denote Canada, France, Germany, Italy, Japan, the United Kingdom, the United States, Brazil, China, India, Indonesia, Mexico, Russia, South Africa and South Korea, respectively.

We subject the underlying models to several diagnostic tests before proceeding with the analysis. Firstly, we examine the stability of potential long-term cointegrating relationships using forward and backward recursively calculated graphs for trace statistic ${ }^{7}$. Visual inspection of the recursive graphs reveals that all the cointegrating relations for all sample countries over the two sub-periods are stable. Further, forward and backward recursive graphs of log-likelihood suggest parameter constancy, thereby ensuring valid identification of the long-run structure. We also perform the test of stationarity of individual variables constructed by Johansen and Juselius $(1990,1992)$ and do not find any variable to be stationary under the chosen cointegration rank ${ }^{8}$.

\section{Long-run Cointegrating Relationships}

After assessing the number of cointegrating relations, we test for the over-identifying restrictions among the variables for each country model before and after the crisis. If the test is not rejected, the restrictions are embodied in the model as long-run steady-state relations. Table 2 displays the Likelihood Ratio (LR) statistic for overidentifying restrictions and the estimated long-run cointegrating relationships, while Table 3 reports the adjustment coefficients denoting the speed of adjustment or correction towards the long-run equilibrium relationships. The LR test results for over-identifying restrictions suggest that all restrictions imposed on the longrun relationships cannot be rejected at the $10 \%$ level. The parameter estimates in each of the estimated long-run cointegrating relationships are found to be highly significant; hence all the long run structures for Cointegrated VAR models are empirically identified. We also check rank condition ${ }^{9}$ of each long-run structure and find the identified long-run equilibrium relationships to be linearly independent of each other. Extensive discussion of the estimated long-run cointegrating relationships (refer Table 2) and the adjustment behaviour (refer Table 3) towards these relationships for a wide range of advanced and emerging economies before and after the crisis is indeed an arduous task. Hence, we limit our analysis to discussing the relationship between the stock prices and policy rate which are the variables of interest in this study.

Forward and backward recursive graphs of trace statistic for all countries have not been displayed due to limited space, but are available on request.

8 Majority of the variables including real output, price index, policy rate and money supply for Saudi Arabia were found to be stationary; hence, Saudi Arabia as a sample emerging market was dropped from the analysis.

9 Results of rank conditions are not reported but are available on request. 


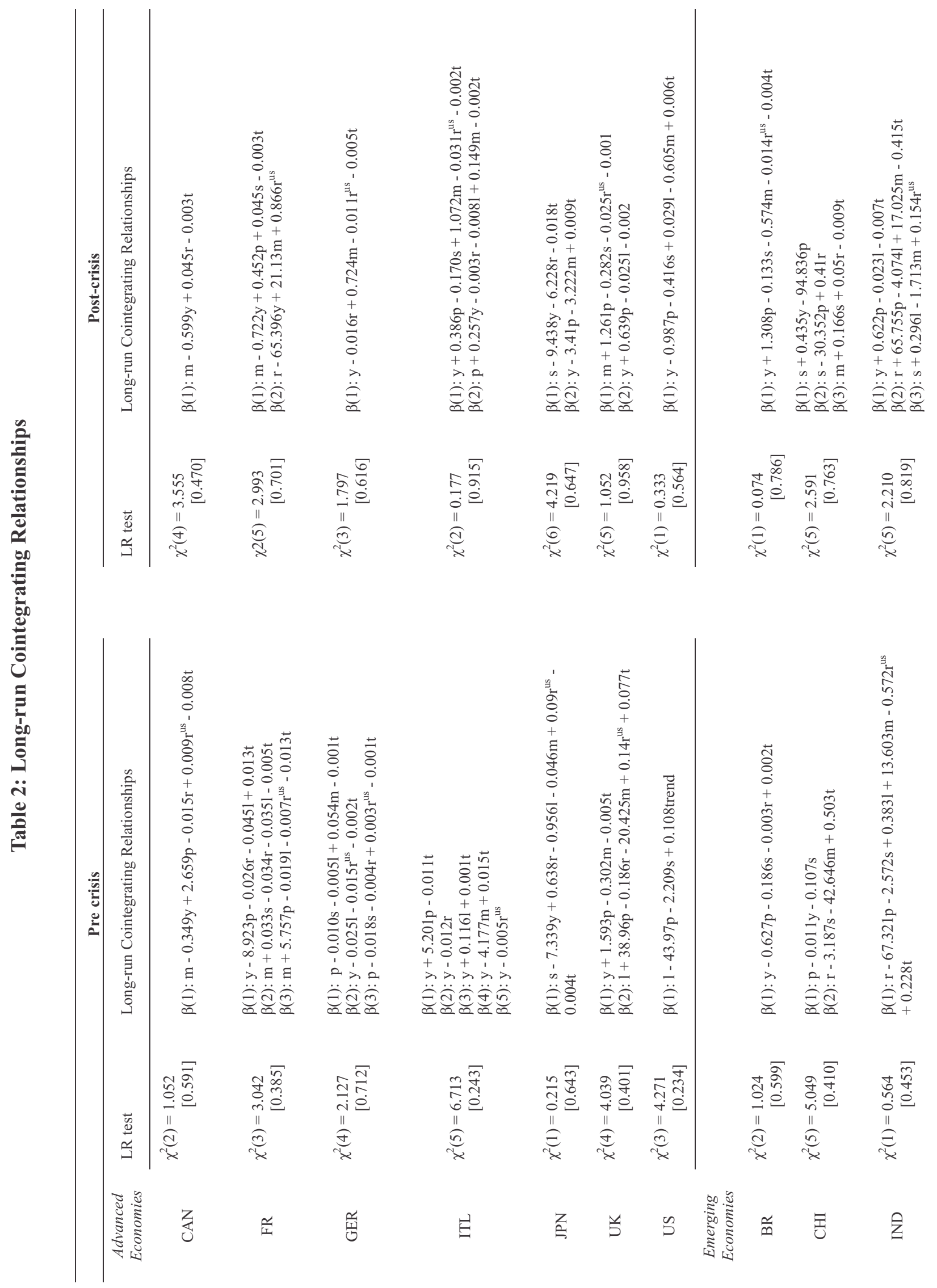




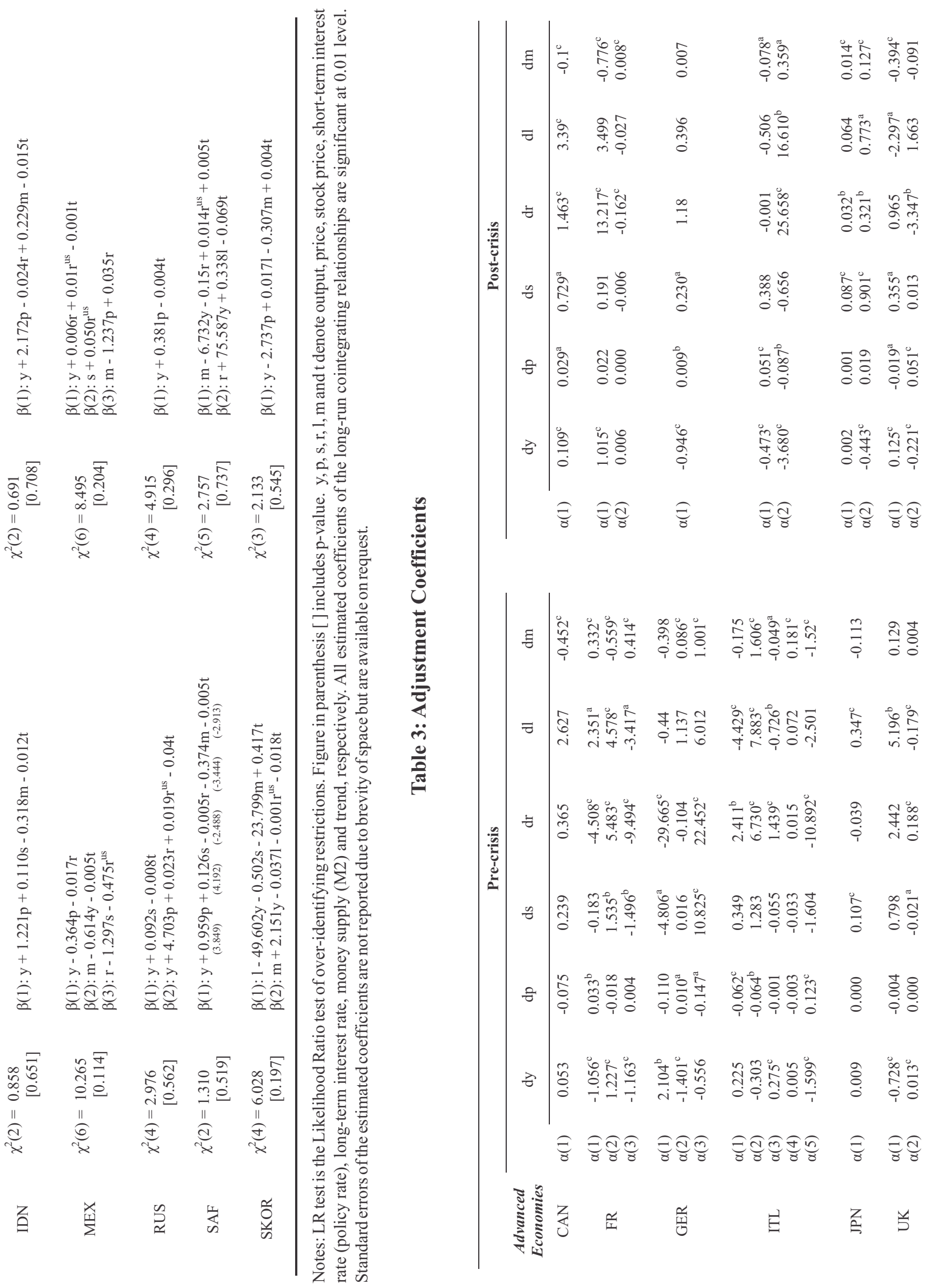




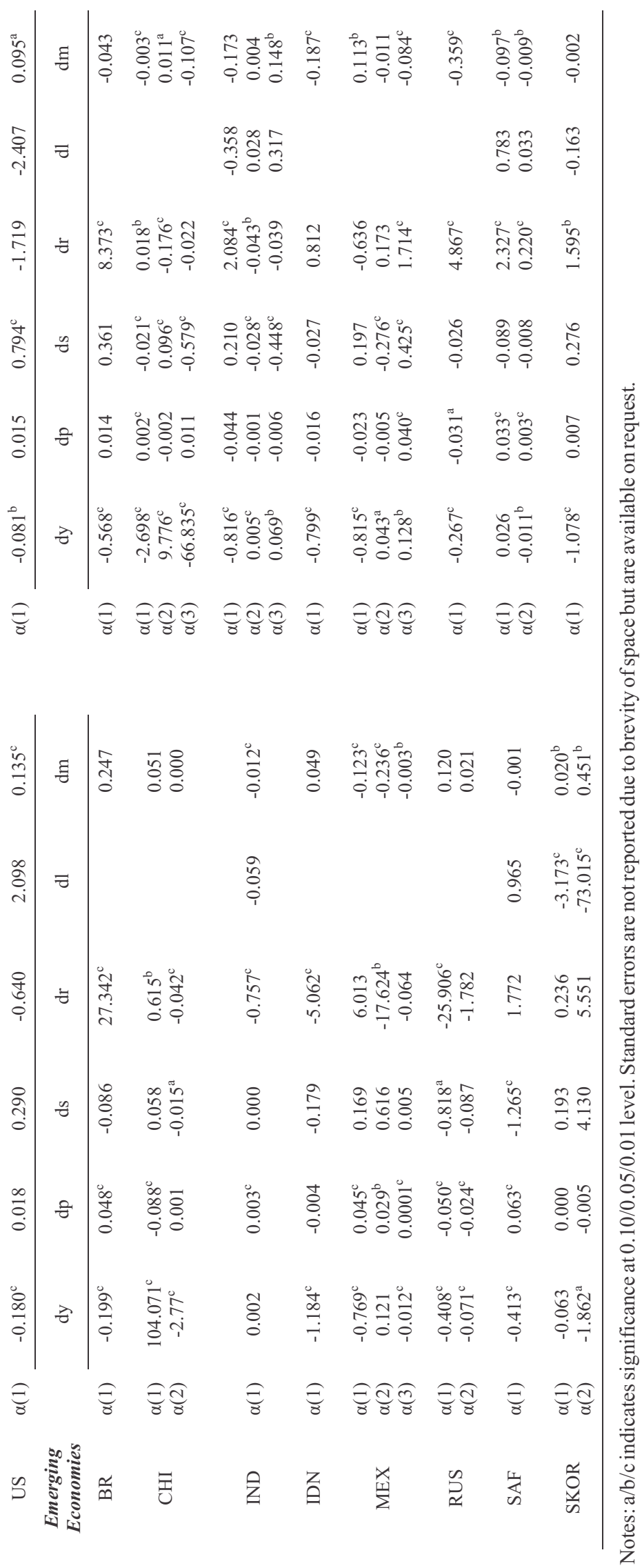


Our results reveal that domestic policy rate and stock prices are often not tied together in long-term equilibrium relationships for the majority of the economies, both advanced and emerging. Among the sample advanced economies, France, Germany and Japan display the cointegrating relationship among policy rate and equity prices in pre-crisis period ${ }^{10}$. Significantly negative bidirectional causality exists between the two variables in France and Germany whereas only stock price reacts negatively to the cointegrating relationship in Japan. However, in the post-crisis period, policy rate and stock prices are found to be positively related in the long run where both of them error correct disequilibrium in the case of France and Japan, but only policy rate exhibits dynamic adjustment in case of Germany. While the theory confirming a negative relationship is found before the crisis, the post-crisis period marks a significant reversal of the relationship. The long-run positive relationship between monetary policy and stock prices can be a result of investors' outlook of interest rate cuts as a signal of worsening economic conditions after the onset of global financial crisis which forced them to revise their expectations of stock prices downward and sell them off in an attempt to "fly to safety" by purchasing relatively safe government bonds (Kontonikas et al., 2013; Kurov and Gu, 2016; Balafas et al., 2018). For emerging economies, only Brazil and India are found to have long-run cointegrating relationships that link policy rate and stock prices before the crisis. Adjustment coefficients suggest that policy rate exhibit dynamic adjustment behaviour towards equilibrium. The cointegrating relationships demonstrate the absence of any link between equity prices and policy rates in all emerging economies after the crisis.

Considering the impact of US monetary conditions on other advanced economies, we find that the monetary policy of the Federal Reserve does not impact the stock market developments in the long-run for a majority of the economies in both pre and post-crisis periods. The long-term negative relationship between equity price and shadow federal funds rate exists in Japan before the crisis, and India and Mexico after the crisis where equity price significantly adjusts to correct long-run disequilibrium. Nevertheless, US monetary policy conditions influence the global output or liquidity conditions as is reflected by its long-run equilibrium relationship with other macroeconomic variables in most economies. This is in line with the finding of Brana et al. (2012) who contend that global excess liquidity created due to ease of monetary conditions had significant spillovers on output and price levels of emerging economies, while the impact on asset prices (including stock) was less clear.

Overall, we find no particular pattern in the estimated long-run cointegrating relationships across the sample countries. The adjustment dynamics also differ for the sample countries in terms of magnitude and significance. This cross-sectional heterogeneity in the results suggests that the long-run interplay between macroeconomic and financial variables is dependent on country-specific characteristics. These results are, in large, consistent with the empirical findings of Belke and Beckmann (2015) that report different patterns and causalities for long-run relationships between monetary policy and stock markets across developing and industrial economies.

\section{Short-run Dynamics}

In this section, we examine the short-run dynamics of monetary policy and stock market interaction by formulating the Structural Vector Error Correction Model (SVECM). Non-stationary variables in the error correction model enter in first differences and the estimated long-run cointegrating relationships are incorporated as pre-determined stationary regressors. Structural identification of the error correction model is achieved through zero short-run restrictions. Our model does not entail the use of long-run restrictions for identification of the

10 Caution needs to be taken while interpreting these results as policy rate and stock prices form a part of the long-run cointegrating relationships which exist along with other variables (refer Table 1). 
structural model because of the existing long-run equilibrium relationships among the variables that differ across countries. We, thus, rely only on contemporaneous restrictions to achieve identification to keep uniformity along each country model. The first-differenced variables are ordered as follows: $X_{t}=\left(\Delta y_{t}, \Delta p_{t}, \Delta m_{t}, \Delta l_{t}, \Delta r_{t}, \Delta s_{t}\right)^{\prime}$. Domestic variables are treated as endogenous in the system and are affected by global exogenous variables (in our case, US monetary policy as a proxy for global monetary policy) but not vice-a-versa. Hence, the shadow federal funds rate is listed first in the ordering of the variables for each country model (except the US), following Galariotis et al. (2018). Thus, the ordering is written as: $X_{t}=\left(\Delta r_{t}^{u s}, \Delta y_{t}, \Delta p_{t}, \Delta m_{t}, \Delta l_{t}, \Delta r_{t}, \Delta s_{t}\right)^{\prime}$. The structural shocks emanating from the variables are: $\varepsilon_{t}=\left(\varepsilon_{t}^{r u s}, \varepsilon_{t}^{y}, \varepsilon_{t}^{p}, \varepsilon_{t}^{m}, \varepsilon_{t}^{l}, \varepsilon_{t}^{r}, \varepsilon_{t}^{s}\right)$, where $\varepsilon_{t}^{r u s}, \varepsilon_{t}^{r}$ and $\varepsilon_{t}^{s}$ are US monetary policy shock, domestic monetary policy shock and equity price shock, respectively. Shocks emerging from other variables are not interpreted. The recursive structure is achieved by assuming that stock prices bear the contemporaneous impact of the shock on any of the variables, but stock price changes do not exert immediate influence on the rest of the variables. The policy rate is allowed to contemporaneously respond to shocks in all variables (except stock prices) reflecting the immediate response of central banks to the macroeconomic shocks. Macroeconomic variables are allowed to respond simultaneously to shocks in other domestic macroeconomic variables, while they respond only with a lag to shocks in monetary and financial variables. Additionally, we re-estimate our baseline model with alternative identification specification of the shock structure to examine the sensitivity of the results wherein we reverse the ordering of money supply and policy rate such that money supply contemporaneously responds to interest rate shocks. Comparing with the baseline results, we find that the alternative ordering of the variables produce qualitatively similar results ${ }^{11}$. Here, we present the results obtained from the baseline specification of the model.

We use impulse response analysis to understand the dynamics of monetary policy and stock market interaction among the sample countries. The orthogonalized impulse responses are generated using Monte Carlo integration with probability bands at 0.16 and 0.84 fractiles based on 1,000 replications. Figure 2 illustrates the responses of stock prices to monetary policy shock up to twelve months for the sample economies. The monetary policy shock is normalized such that it leads to one percentage (100 basis-points) decrease in the policy rate, reflecting expansionary monetary policy shock. As is evident from the figure, responses of the shocks subside in the long run (approximately 12 months) because of the stationarity of the data series. The theory-confirming negative impact of monetary policy on equity prices is found in the case of Canada, Germany, the US, China, Indonesia, Mexico, Russia, South Africa and South Korea in the pre-crisis period. Among these, the impact is found to be significant only for Canada, the US, Indonesia, Mexico and Russia. On the other hand, an unexpected $100 \mathrm{bp}$ decrease in the policy rate decreases the stock prices in France, Italy, Japan, UK, Brazil and India. A closer inspection into the dynamics of these economies reveals that the domestic monetary policy shock has an insignificant impact on their macroeconomic variables including real activity, prices and money supply, as well as the long-term interest rate ${ }^{12}$, reflecting the inability of their respective central banks in influencing domestic macroeconomic conditions in the short-run. After the crisis, Italy and Japan exhibit a significantly positive response of stock prices to unexpected policy rate cuts. This phenomenon can potentially be explained by high uncertainty and recessionary tendencies coupled with low and even negative interest rate environment that characterizes these economies.

11 Results are not presented due to brevity of space but are available on request.

12 Refer Appendix B1-B4 for impulse responses of output, prices, money supply and long-term interest rate to domestic monetary policy shock. 


\section{Figure 2: Response of Equity Prices to Domestic Monetary Policy Shock}

\section{Response of Equity Price to Domestic Monetary Policy Shock}
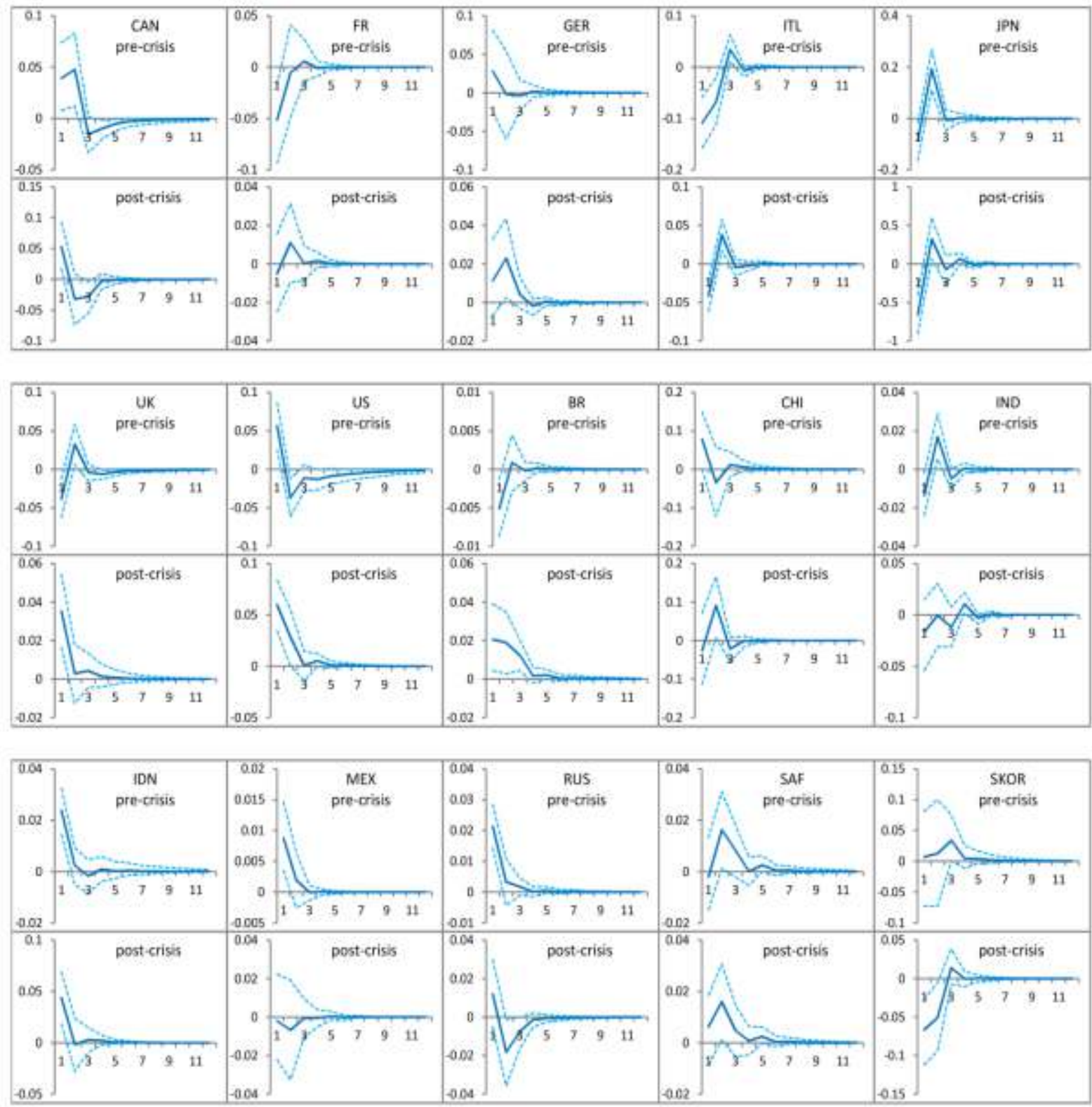

The figure displays impulse responses (solid lines) of equity prices to domestic monetary policy shock for the sample countries in pre-crisis (upper panel) and post-crisis (lower panel) period. The dashed lines represent probability bands at 0.16 and 0.84 fractiles which correspond to one standard deviation and are estimated using Monte Carlo integration. Monetary policy shock is normalized such that it leads to one percentage decrease in the policy rate, implying expansionary monetary policy shock. Impulse responses are plotted for 12 time horizons (represented on the horizontal axis).

The reaction of central banks to domestic equity price shocks, on the other hand, is found to be rather limited. Unexpected equity price changes exert significant policy rate adjustments only in Canada, Italy, UK, Indonesia, Russia and South Africa in pre-crisis period (refer Figure 3). Except for Canada and UK, central banks of the rest of the economies react by cutting the policy rates to positive equity price shocks. After the crisis, the majority of the 
central banks of advanced economies respond by tightening their monetary policy to positive equity price shocks. This indicates the systematic response of central banks to rein excessive stock price fluctuations as they move away from their fundamental values and thus, highlights the importance of stock price movements as a driver of monetary policy decisions. Our results suggest that this evidence in the case of emerging economies is weak, except Indonesia and South Africa where central banks significantly respond through policy rate cuts after positive equity price shocks. Considering the response of real output and inflation to unexpected changes in equity prices, we find that the equity price shocks lead to an increase in aggregate demand and inflation, but is insignificant for most of the cases. This explains the weak transmission of monetary policy through the asset price channel.

Figure 3: Response of Policy Rate to Equity Price Shock

\section{Response of Policy Rate to Equity Price Shock}
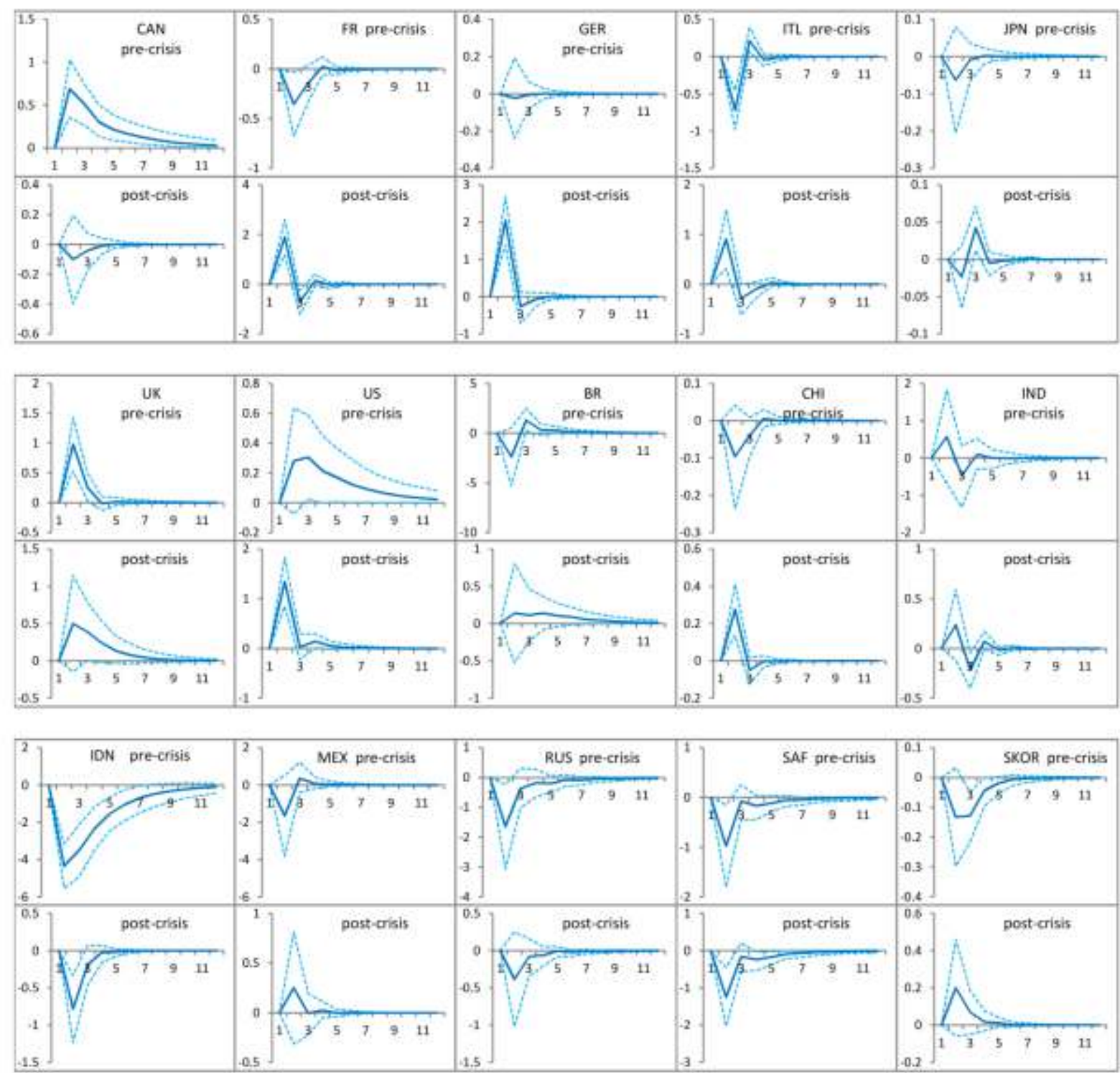

The figure displays impulse responses of policy rates to equity price shock for the sample countries in pre-crisis (upper panel) and postcrisis (lower panel) period. Equity price shock is normalized such that it leads to one percentage increase in the equity prices. Impulse responses are plotted for 12 time horizons (represented on the horizontal axis). 
Turning our attention to the impact of global monetary policy shock, we find that an unexpected $100 \mathrm{bp}$ decrease in shadow federal funds rate induces a rise in stock prices for a majority of the economies in the pre-crisis period (refer Figure 4). However, expansionary US monetary policy shock significantly drives stock prices only in France and Germany. In the post-crisis period, the impact of US monetary policy shock on equity prices reverses for most of the emerging economies but is insignificant. While equity prices react insignificantly, unexpected changes in the US monetary policy induce a significant effect on domestic policy rates (refer Appendix D5) indicating that central banks closely monitor the global monetary conditions and respond accordingly to ensure domestic macroeconomic stability. We observe a significantly positive response of policy rate in the majority of the economies to the US monetary policy shock before the crisis suggesting monetary policy concord across the economies. The post-crisis period marks a reversal in the response for emerging markets as an unanticipated decrease in shadow federal funds rate triggers an increase in the policy rate, though the effect is found to be insignificant. Large scale asset purchases by Federal Reserve following the crisis feed into the global economies apparently through increased liquidity among international investors. This is reflected in the significantly positive effect of the money supply to US monetary policy shocks (refer Appendix D3). Further, the expansionary monetary policy of Federal Reserve shocks brought a sizable fall in the long-term government securities yield after the crisis (refer Appendix D4). The only exception is India where an unexpected $100 \mathrm{bp}$ decrease in the shadow federal funds rate triggers an almost $24 \mathrm{bp}$ increase in the long-term yields. Overall, our findings underline the importance of US monetary policy shock in influencing the policy rate, long-term interest rate and money supply of the domestic economy.

Figure 4: Response of Equity Price to US Monetary Policy Shock

\section{Response of Equity Price to US Monetary Policy Shock}
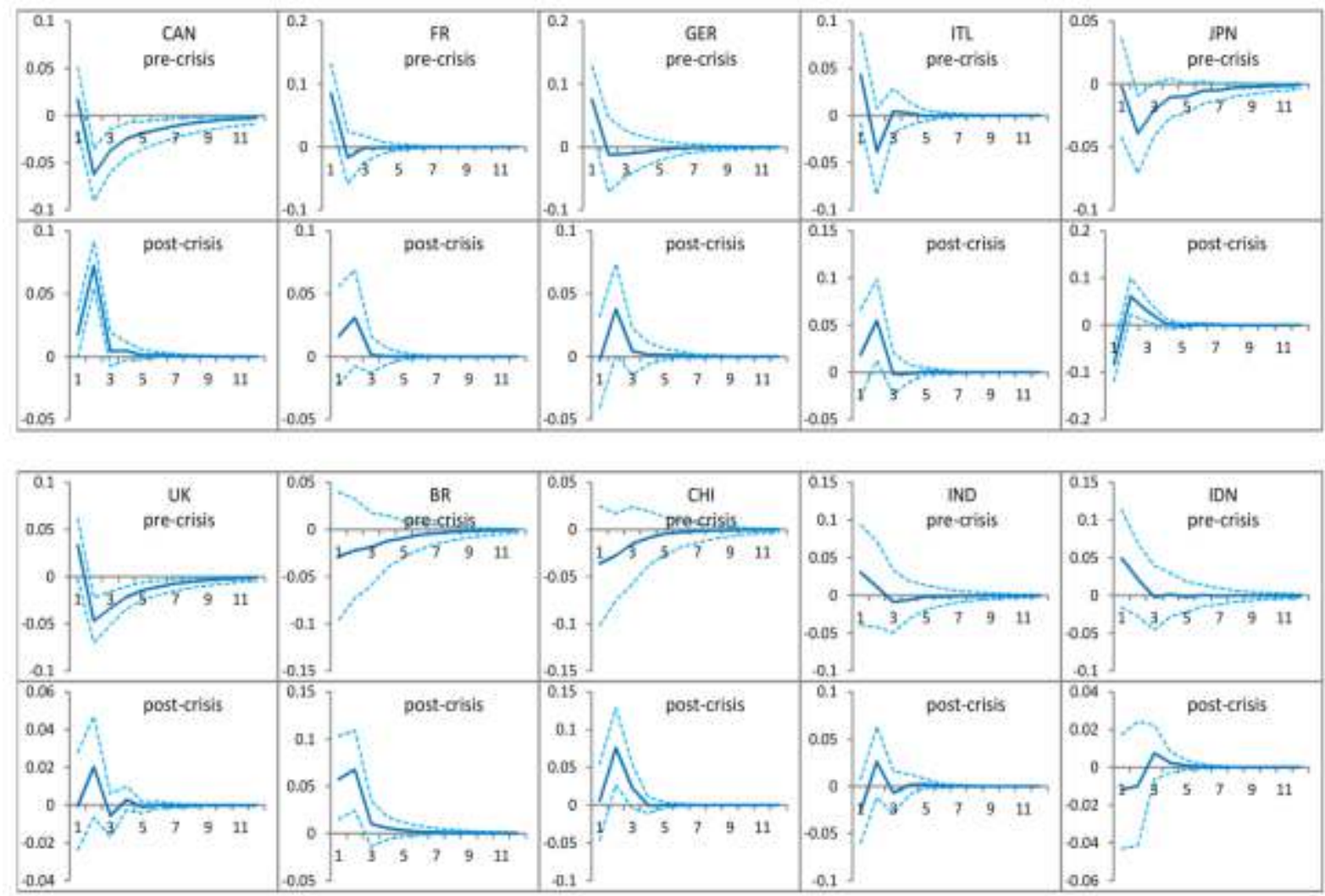


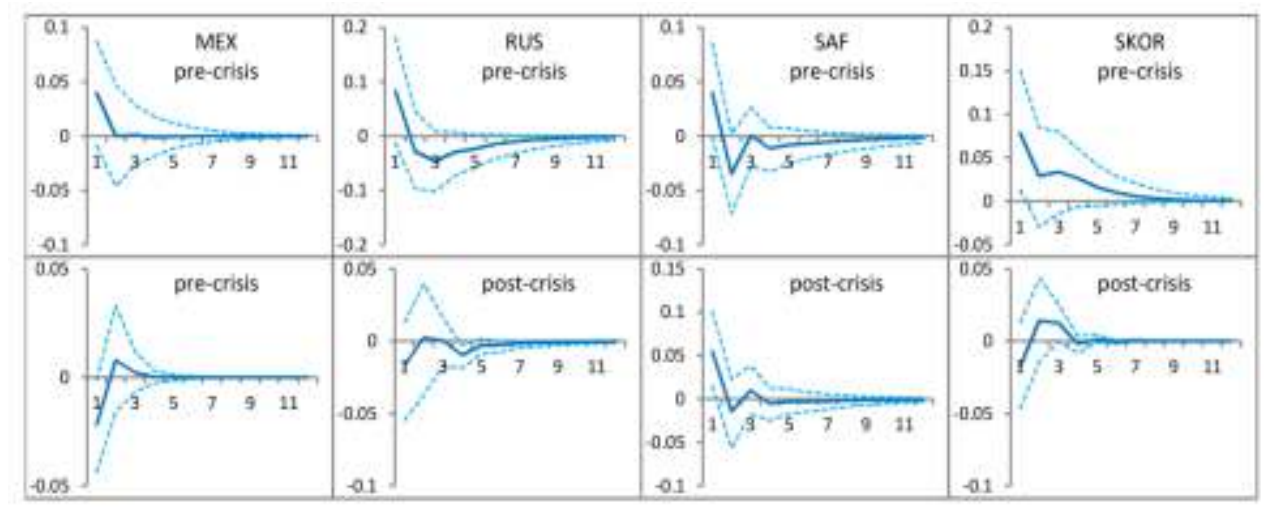

The figure displays impulse responses of equity prices to US monetary policy shock for the sample countries in pre-crisis (upper panel) and post-crisis (lower panel) period. US monetary policy shock is normalized such that it leads to one percentage decrease in the shadow federal funds rate, implying expansionary US monetary policy shock. Impulse responses are plotted for 12 time horizons (represented on the horizontal axis).

\section{SUMMARY AND CONCLUSION}

This paper investigates monetary policy and stock market interaction across 15 economies, both advanced and emerging over the period from January 1999 to December 2017. Structural Cointegrated VAR model is employed to examine the long-run equilibrium relationships and short-run dynamics of the interrelationship of domestic monetary policy with stock markets for these economies. We, further, examine the role of US monetary policy in influencing the stock markets of the sample economies which enables us to get a perspective of the importance of global monetary conditions relative to the domestic monetary policy. The analysis is conducted for two sample periods - before and after the global financial crisis of 2008 thereby providing a comprehensive account of the relationship in pre and post-crisis periods. Long-run cointegration analysis results reveal that domestic policy rate and stock prices are often not tied together in long-term equilibrium relationships for the majority of the economies, both advanced and emerging. Among the advanced economies, France, Germany and Japan display the cointegrating relationship of policy rate and equity prices. However, the relationship among these countries differs in terms of the sign, magnitude and adjustment dynamics in the pre and post-crisis periods. While the theory confirming negative relationship is found before the crisis, the period after the crisis marks a significant reversal of the relationship which can be explained by investors' outlook of interest rate cuts as a signal of worsening economic conditions after the onset of the global financial crisis, forcing them to revise their expectations. For emerging economies, only Brazil and India are found to have a long-run cointegrating relationship that links policy rate and stock prices in the pre-crisis period while the post-crisis period demonstrates the absence of any link between them in all emerging economies. Further, US monetary conditions do not influence stock market developments in majority economies in both before and after the crisis. Nevertheless, US monetary policy conditions influence the global output or liquidity conditions in the long run as is reflected by its long-run equilibrium relationship with other macroeconomic variables in most of the economies. Short-run dynamics demonstrate the significantly negative impact of domestic monetary policy on equity prices in Canada, the US, Indonesia, Mexico and Russia. On the other hand, France, Italy, Japan, UK, Brazil and India display a positive impact of monetary policy shock on equity prices. A closer inspection into the dynamics of these economies reveals that domestic monetary policy shock leads to an insignificant impact on their macroeconomic variables reflecting the inability of their respective central banks in influencing domestic macroeconomic conditions. After the 2008 crisis, Italy and Japan exhibit a significantly positive response of equity prices to unexpected contractionary monetary policy which can be explained by high uncertainty and recessionary tendencies in these economies. Further, we find that the reaction of central banks to domestic equity price shocks 
is limited. The influence of US monetary policy shock in driving equity prices is also found to be insignificant for the majority of the economies both before and after the crisis. However, domestic policy rates significantly respond to unexpected changes in the US monetary policy suggesting monetary policy concord. Results also reveal a significantly positive effect of the money supply to US monetary policy shocks in the post-crisis period reflecting increased liquidity among international investors as a consequence of large scale asset purchases following the crisis.

\section{RECOMMENDATIONS AND IMPLICATIONS}

Our empirical findings have important implications for central bankers. The monetary policy actions of central banks have a considerable impact on the stock markets in the short-run. However, they generally do not 'lean against the wind' by responding to excessive fluctuations in the asset prices to ensure financial stability. It is pertinent for central bankers to develop a credible monetary policy framework by strengthening the asset price channel of monetary policy transmission mechanism as it plays a determining role in investor's portfolio decisions. Weak monetary policy transmission to real economy induces investors to undertake risk assessment and alter their expectations about future economic outlook which may lead to the unintended influence of monetary policy actions on stock market developments. The relationship between monetary policy and stock prices typically reverses during times of financial distress and uncertain macroeconomic environment. The policy actions of central banks may yield unfavourable outcomes during such times. For instance, aggressively pursuing an expansionary monetary policy to stimulate the economy after the crisis may lead to excessive risk-taking and bubble formation. Hence, appropriate policy response while giving due cognizance to the negative consequences is required to mitigate adversities in the aftermath of the crisis. Global monetary conditions also merit the attention of central bankers in the conduct of monetary policies as they play an important role in driving domestic macroeconomic and liquidity conditions. Our analysis did not incorporate variables like fiscal policy, exchange rate, interest rate differential, etc. that may influence the relationship between monetary policy and stock prices and is left for future research on this topic. Further, future studies can explore the asymmetric impacts of monetary policy on stock prices depending on the state of the stock markets i.e. bull and bear phases. Following the unconventional monetary policies undertaken by the central banks of advanced countries, investors and financial institutions started taking excessive risk leading to financial instability. Hence, studying the risk-taking channel of monetary policy can provide another important avenue for future research.

\section{REFERENCES}

Abouwafia, H.E., \& Chambers, M. J. (2015). Monetary policy, exchange rates and stock prices in the Middle East region. International Review of Financial Analysis, 37, 14-28.

Angelini, P., A. Nobili, and C. Picillo. (2011). The Interbank Market After August 2007: What Has Changed, and Why?. Journal of Money, Credit and Banking, 43(5): 923-958.

Balafas, N., Florackis, C., \& Kostakis, A. (2018). Monetary policy shocks and financially constrained stock returns: The effects of the financial crisis. International Review of Financial Analysis, 58, 69-90.

Belke, A., \& Beckmann, J. (2015). Monetary policy and stock prices-Cross-country evidence from cointegrated VAR models. Journal of Banking \& Finance, 54, 254-265.

Brana, S., Djigbenou, M. L., \& Prat, S. (2012). Global excess liquidity and asset prices in emerging countries: A PVAR approach. Emerging Markets Review, 13(3), 256-267.

Cologni, A., \& Manera, M. (2008). Oil prices, inflation and interest rates in a structural cointegrated VAR model for the G-7 countries. Energy economics, 30(3), 856-888.

Eksi, O., \& Tas, B. K. O. (2017). Unconventional monetary policy and the stock market's reaction to Federal 
Reserve policy actions. The North American Journal of Economics and Finance, 40, 136-147.

Fausch, J., \& Sigonius, M. (2018). The impact of ECB monetary policy surprises on the German stock market. Journal of Macroeconomics, 55, 46-63.

Galariotis, E., Makrichoriti, P., \& Spyrou, S. (2018). The impact of conventional and unconventional monetary policy on expectations and sentiment. Journal of Banking \& Finance, 86, 1-20.

Giese, J. V., \& Tuxen, C. K. (2007). Global liquidity and asset prices in a cointegrated VAR. Nuffield College, University of Oxford, and Department of Economics, Copenhagen University, 1-28.

Hafer, R. W., \& Jansen, D. W. (1991). The demand for money in the United States: evidence from cointegration tests. Journal of Money, Credit and Banking, 23(2), 155-168.

Ioannidis, C., \& Kontonikas, A. (2008). The impact of monetary policy on stock prices. Journal of policy modeling, 30(1), 33-53.

Juselius, K. (2006). The cointegrated VAR model: methodology and applications. Oxford university press.

Kontonikas, A., MacDonald, R., \& Saggu, A. (2013). Stock market reaction to fed funds rate surprises: State dependence and the financial crisis. Journal of Banking \& Finance, 37(11), 4025-4037.

Kurov, A., \& Gu, C. (2016). Monetary Policy and Stock Prices: Does the "Fed Put" Work When It Is Most Needed?.Journal of Futures Markets, 36(12), 1210-1230.

Latha, K., Gupta, S., \& Ghosh, R. (2017). Interest Rate Volatility and Stock Returns: A GARCH $(1,1)$ Model. Ramanujan International Journal of Business and Research, Volume 2, 57-74.

Li, Y. D., İşcan, T. B., \& Xu, K. (2010). The impact of monetary policy shocks on stock prices: Evidence from Canada and the United States. Journal of International Money and Finance, 29(5), 876-896.

Sehgal, S., Gupta, P. and Deisting, F. (2016). Assessing time varying stock market integration in Economic and Monetary Union for normal and crisis periods, The European Journal of Finance, DOI: 10.1080/1351847X.2016.1158727

Suhaibu, I., Harvey, S. K., \& Amidu, M. (2017). The impact of monetary policy on stock market performance: Evidence from twelve (12) African countries. Research in International Business and Finance, 42, 13721382.

Trichet, J.-C. (2010). State of the Union: The Financial Crisis and the ECB's Response Between 2007 and 2009. Journal of Common Market Studies, 48 (1): 7-19.

Wu, J. C., \& Xia, F. D. (2016). Measuring the macroeconomic impact of monetary policy at the zero lower bound. Journal of Money, Credit and Banking, 48(2-3), 253-29. 